\title{
Decision-making to perform elective surgery for patients with proximal thoracic aortic pathology: A European perspective
}

Martin Czerny, MD, MBA, ${ }^{\mathrm{a}, \mathrm{b}}$ Bartosz Rylski, MD, ${ }^{\mathrm{a}, \mathrm{b}}$ Alessandro Della Corte, $\mathrm{MD},{ }^{\mathrm{c}}$ and Tobias Krüger, $\mathrm{MD}^{\mathrm{d}}$

Feature Editor's Introduction-This issue of the Journal features an interesting Expert Opinion by Czerny and colleagues regarding risk prediction for dissection formation in patients with thoracic aortic aneurysm disease. The adverse structural and biochemical changes that develop in the aorta to cause aneurysm disease have been well studied and mechanistically profiled, as has the natural history of this disease. Although our overall understanding of thoracic aortic aneurysms has advanced, it can be argued that our ability to select patients at the appropriate time for surgical or endovascular intervention has not.

Current guidelines regarding aortic size indications for invasive treatment have focused primarily on absolute arterial diameter and, to a lesser extent, diameter indexed to body surface area or cross-sectional area measurements. To date, attempts to enhance the sensitivity and sensitivity of our predictive ability using plasma profiling of proteases and other biochemical intermediates or stress measurements within the aortic wall have proven tedious, imprecise, costly, and perhaps most important, clinically impractical given our current technology. Is there something else that can be used?

Czerny and colleagues review the current thinking and published evidence regarding the use of aortic length as an additional assessment. Present studies have shown that that there may be clear value in adding this parameter, which is attractive because aortic length can be easily measured and followed using the same studies obtained to measure diameter. The authors discuss the potential role of aortic diameter measurement in both degenerative and heritable aortic aneurysm disease states, and introduce a preliminary algorithm for its clinical use.

\footnotetext{
From the ${ }^{\mathrm{a}}$ Department of Cardiovascular Surgery, University Heart Center Freiburg, Bad Krozingen, Germany; ${ }^{b}$ Faculty of Medicine, Albert Ludwigs University Freiburg, Freiburg, Germany; ${ }^{\mathrm{c} D}$ Department of Translational Medical Sciences, University of Campania “L. Vanvitelli," Cardiac Surgery Unit, Monaldi Hospital, Naples, Italy; and ${ }^{\mathrm{d}}$ Department of Thoracic and Cardiovascular Surgery, University Medical Center, Tübingen, Germany.

Disclosures: Authors have nothing to disclose with regard to commercial support.

Received for publication Dec 28, 2020; revisions received Jan 13, 2021; accepted for publication Jan 22, 2021; available ahead of print Feb 27, 2021.

Address for reprints: Martin Czerny, MD, MBA, Department of Cardiovascular Surgery, University Heart Center Freiburg, Albert Ludwigs University Freiburg, Faculty of Medicine, Hugstetterstrasse 55, D-79106 Freiburg, Germany (E-mail: martin.czerny@universitaets-herzzentrum.de).

J Thorac Cardiovasc Surg 2022;163:2025-30

$0022-5223 / \$ 36.00$

Copyright (c) 2021 by The American Association for Thoracic Surgery

https://doi.org/10.1016/j.jtcvs.2021.01.141
}

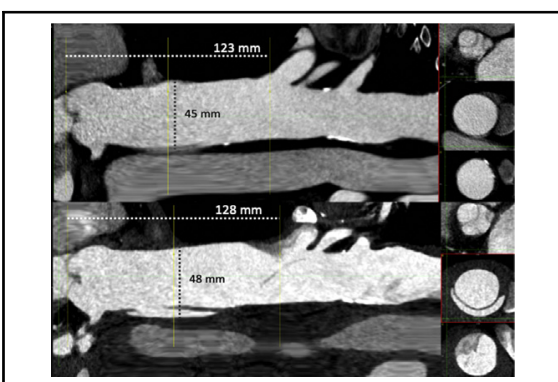

Proximal thoracic aorta before and after acute TAAD.

\section{CENTRAL MESSAGE \\ Proximal thoracic aortic length has entered the arena of surrogate predictors to indicate surgical treatment for proximal thoracic aortic pathology and is here to stay.}

See Commentaries on pages 2031 and 2034

This Expert Opinion is a welcome and timely addition to the Journal and should stimulate further study into the feasibility and value of incorporation of aortic length measurements into the mainstream of clinical thoracic aortic surgical practice.

\section{John S. Ikonomidis, MD, PhD}

For many years, risk assessment for indicating elective surgery for proximal thoracic aortic pathology to prevent acute type A aortic dissection (TAAD) or root/ascending aortic rupture has been based largely on diameter thresholds. Recent knowledge, having been created by groups in the United States and in Europe, has challenged this concept and brought new surrogate predictors into discussion to optimize the timing and indication of preventive surgery.

The intent of this article is to provide the interested reader with a glimpse into the details of the current discussions about changing criteria for indicating elective surgery for proximal thoracic aortic pathology and how this can be safely implemented into clinical practice. 


\section{HOW CURRENT RECOMMENDATIONS DEVELOPED}

Plausibility and eyewitnessing confirm that acute TAAD results from rupture in the aortic intima secondary to wall stress exceeding wall stability, and we know from engineering that wall stress in a tube increases with diameter (Barlow's formula). The results of the seminal studies by the Yale group ${ }^{1}$ from the turn of the millennium fit this picture: The risk of acute TAAD increases with aortic diameter. That is the basis of the recommendation in the current guidelines. ${ }^{2,3}$

There is consensus that most acute TAADs occur in aortas below the diameter threshold of $5.5 \mathrm{~cm}$ where elective surgery is currently indicated according to current guidelines. ${ }^{1,4-7}$ This is clearly due to the higher incidence of ectatic aortas in the population and is not contradictory to the correlation of diameter and dissection risk. This effect has been termed the "aortic size paradox." ${ }^{8}$ However, we know that aortic diameter acutely increases during the process of dissection itself, making it challenging to calculate predissection dimensions. ${ }^{5,7}$ A good share of even already dissected aortas are less than $5.5 \mathrm{~cm}$ in diameter. So why not simply decrease the threshold diameter? A reduction of the threshold diameter would result in more patients with an indication for preventive surgery, therefore exposed to the risk of elective surgery to prevent one acute TAAD. ${ }^{9,10}$ Although the risk of proximal thoracic aortic surgery is low in expert hands and high-volume centers, this high safety net cannot be provided everywhere. Because there is a clear relation between volume and outcome in aortic surgery, this further underlines the need for the creation of aortic centers where all treatment options are available under one umbrella and where the highest level of expertise is provided. ${ }^{11}$

Obviously, effective prevention and prophylactic surgery are the best strategy to treat a catastrophic disease such as acute TAAD, but basing TAAD prophylaxis just on the aortic diameter is arbitrary and simplifying. If we want to rethink acute TAAD prophylaxis, we have to ask ourselves from a logical standpoint that other parameters can be used to predict acute TAAD.

\section{MORPHOLOGY}

Traditionally, aortic diameter is the parameter of choice for risk prognostication because it is easily recordable, but as described, an absolute threshold ascending aorta diameter alone does not enable efficient prognostication of acute TAAD.

Given the correlation of aortic morphology with anthropometry, indexed threshold parameters for diameter have been discussed repeatedly. ${ }^{3}$ Indexing to body surface area (BSA) is somehow suggested by guidelines, at least for small-size patients, yet without any supporting evidence of superior sensitivity and specificity compared with the absolute diameter in predicting acute aortic events in the general population. Indexing to BSA implies that the same patient with the same aortic diameter can hypothetically be indicated for surgery or not after losing or gaining body weight. The Yale group preferred body height over BSA with the arguments that it is irrelevant for the aorta whether the body is slim or obese, and that body weight may change throughout one's lifetime. ${ }^{12,13}$ Most multivariate analyses independently from each other revealed BSA as a predictor, in addition to age and gender. ${ }^{9,14}$

Beyond diameter, the length of the ascending aorta has become the focus of interest in recent years since it became measurable using contemporary postprocessing image reconstruction software. ${ }^{4,5,15}$ Aortic elongation is interesting for various reasons. On the one hand, like diameter, it is a dimension of physiologic age-related degeneration and pathological aneurysm formation. On the other hand, longitudinal elasticity is an essential component of the Windkessel function, and a longitudinal material failure would explain an often horizontally oriented primary entry tear in acute TAAD. In recent years, evidence showed that aortic elongation is a risk factor for TAAD, ${ }^{14-18}$ and the Yale group recently added longitudinal survival data enabling risk stratification. ${ }^{12}$ In that cohort, the diameter was normally distributed with a mean of $4.8 \pm 0.7 \mathrm{~cm}$, approximately $16 \%$ of patients had diameters of $5.5 \mathrm{~cm}$ or greater. The central finding is the 5-fold increment of aortic events in aortas with a length $13 \mathrm{~cm}$ or more compared with those of less than $9 \mathrm{~cm}$, and the KaplanMeier analysis showing a better event-free survival of patients with ascending aorta length less than $12 \mathrm{~cm}$. This confirms and substantiates recent European findings that patients with an aortic length of $12 \mathrm{~cm}$ represent a risk group. ${ }^{4}$ The Yale group goes a step further by reporting that $70 \%$ of patients with acute TAAD with diameters less than $5.5 \mathrm{~cm}$ had an ascending aorta length of $11.0 \mathrm{~cm}$ or more, suggesting a potential additive value of aortic length in predicting the risk of acute aortic events. Figure 1 shows a proximal thoracic aorta before and after acute TAAD showing the acute diameter increase without acute length increase.

As with diameter, the Yale group indexed the aortic length exclusively to body height, which seems logical and pragmatic, but at the same time arbitrary against the background that in the same article a correlation of the length with age is demonstrated, which is supported by the literature. ${ }^{4}$ The Yale group reports a mean growth rate of $0.18 \mathrm{~cm}$ per year, which to us seems rapid. Other articles have claimed $0.21 \mathrm{~cm}$ per decade, which appears more plausible. ${ }^{4}$ Multivariate prediction would be logical and helpful. In the recent Yale report, the aortic height index, arithmetic sum of ascending aorta diameter, and length indexed to 


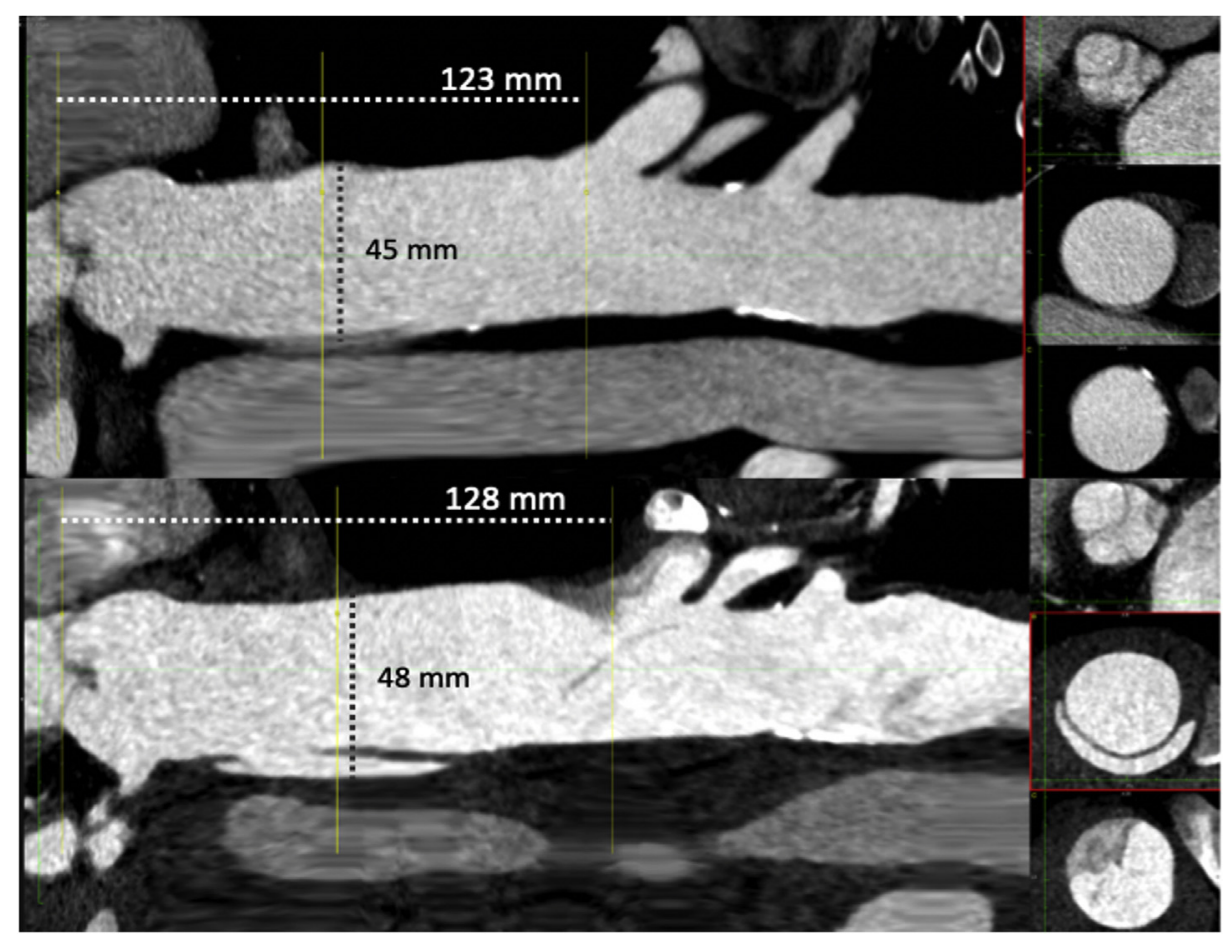

FIGURE 1. Proximal thoracic aorta before and after acute TAAD.

body height are given, and an aortic height index of 10 is reported as moderate risk.

Multifactorial prediction models for ascending aorta diameter and length have been provided (eg, www. aorticcalculator.com). Admittedly, these projects are based on smaller collectives compared with the Yale figures and lack the longitudinal data. ${ }^{4,9,14}$

Morphology is not just about diameter and length. Bicuspid aortic valve (BAV) used to be an accepted risk factor for acute aortic syndromes, and in the past the guidelines highlighted a higher risk of acute TAAD for patients with $\mathrm{BAV}$, therefore recommending surgery at $5.0 \mathrm{~cm}$ or even earlier. ${ }^{5,6}$ In the TAIPAN database, comparable to other studies, a frequency of $7.7 \%$ of BAV in patients with acute TAAD, twice as much as in healthy controls $(3.2 \%)$, has been seen. ${ }^{7}$ In addition, patients with BAV had dissection earlier in life. ${ }^{19}$ The BAV frequency in patients with ectasia and aneurysm was approximately $30 \%$ in Taipan, and it was approximately $20 \%$ in the recent Yale work. ${ }^{10}$ However, its role was recently questioned, and recent specific guidelines were changed to a phenotype-guided approach for BAVassociated aortopathy with indication at $5.0 \mathrm{~cm}$ in the root phenotype and $5.5 \mathrm{~cm}$ (as for the non-BAV population) in the more frequent ascending phenotype. ${ }^{20,21}$ The concept of valve morphology and aorta phenotype-based stratification is particularly important with a view to future multifactorial risk models.

Aortic arch morphology variants have been discussed repeatedly. The Yale group reports a bovine arch frequency of $17 \%$, but its role as a risk factor for acute TAAD could not be clearly established. ${ }^{12,22}$ Furthermore, recent investigations by Della Corte and colleagues (unpublished data) suggested that in some cases elongation was accompanied by an exaggerated angulation of the ascending axis with respect to the proximal arch axis, which was uniquely associated with TAAD. Finally, the presence of renal and hepatic cysts, with or without underlying genetic syndromes, has been reported as a risk factor of acute TAAD formation. ${ }^{23}$ Consequently, we should rethink the topic of extra-aortic morphologic predictors.

\section{GENETICS AND FAMILY HISTORY}

The multitude of genetic conditions that come along with an increased risk for acute TAAD has been reviewed and is beyond the scope of this article. ${ }^{24}$ In our opinion, one should clearly distinguish between genetically determined acute aortic conditions and nongenetically triggered conditions. We are also aware that with the advancement of knowledge, more patients will move from the second to the first group. However, we are particularly interested in predicting acute TAAD in patients without defined genetic risk factors. In both the European and American guidelines, it is recommended to investigate first-degree relatives of a subject with thoracic aortic aneurysms and dissections to identify a familial form (Class I, level of evidence C), and the 2010 American guidelines recommend surgery for patients with a genetically mediated aneurysm at 4.0 to $5.0 \mathrm{~cm} .^{3}$ In real life, we repeatedly 
see patients with a positive family history but without a defined genetic condition, but they are deemed to have a higher risk. ${ }^{19}$ If these patients present with an ascending aorta ectasia, the question arises when to operate on them preventively. Basically, positive family history would reasonably be another factor in the ideal multifactorial risk assessment system.

\section{BIOMECHANICS AND FUNCTIONAL IMAGING}

The functional role of the ascending aorta is well known as the "Windkessel effect," and aortic compliance $(\mathrm{C}=\mathrm{dV}$ / $\mathrm{dP}$ ) is its dimension. Compliance results from the stressstrain relation of the aortic wall, which typically has directional, regional, and age-related differences and is correlated with histopathologic alterations. ${ }^{25,26}$ Furthermore, the aortic wall is characterized by a failure stress that, again, has directional and regional differences and probably differs between the intimal and medial layers of the aorta. Specifically, longitudinal wall failure has been hypothesized being involved in acute TAAD pathogenesis. Efforts were made to visualize the wall stress in the ascending aorta in computed tomography using the finite elements method ${ }^{27}$ displaying distinctive regions of increased wall stress. ${ }^{28}$ In addition to this intramural stress, blood flow causes wall shear stress and contemporary 4-dimensional flow magnetic resonance imaging is capable of visualizing it. Positron emission tomography computed tomography is capable of visualizing regions of metabolic activity in aneurysms, which also has been evaluated being predictive for aortic events. ${ }^{29}$ Computational fluid dynamics is a method of simulating blood flow according to assumptions of pressure and morphologic features of the vessel and is capable of predicting wall shear stress as well. However, it has to be taken into account that determining true wall stress also needs knowledge of arterial blood pressure inside the aorta, which cannot be gleaned from imaging alone. A lot of research is currently under way investigating the aforementioned modalities of functional imaging. Although up to date, no thresholds or reliable predictors for acute TAAD development are defined. It is likely that such parameters will emerge in the near future, blazing the trail of these modalities into acute TAAD prognostication.

\section{INTEGRATIVE MULTIFACTORIAL PREDICTION OF ACUTE TAAD}

With respect to future aortic risk assessment and the generation of recommendations and guidelines for preventive proximal thoracic aortic surgery, our first aim must be not to harm patients: primum non nocere. In other words, our method of risk assessment must have a high specificity for patients at risk for acute TAAD. The second aim must be to prevent as many acute TAADs as possible (high sensitivity for patients at risk for acute TAAD). Ascending aorta length can be regarded as correlated to the risk of acute TAAD development. This has now been independently described by 3 different groups from Europe and the United States. ${ }^{4,12,14,16-18}$ Furthermore, there seems to be consensus that ascending aorta length should be measured as the distance between the aortic valve annulus and the offspring of the brachiocephalic trunk. So basically, for these 2 statements, we have level $\mathrm{C}$ evidence. We should further include ascending aorta length in our decisionmaking. But what should be the thresholds?

\section{Multifactorial risk prediction for acute type A aortic dissection}

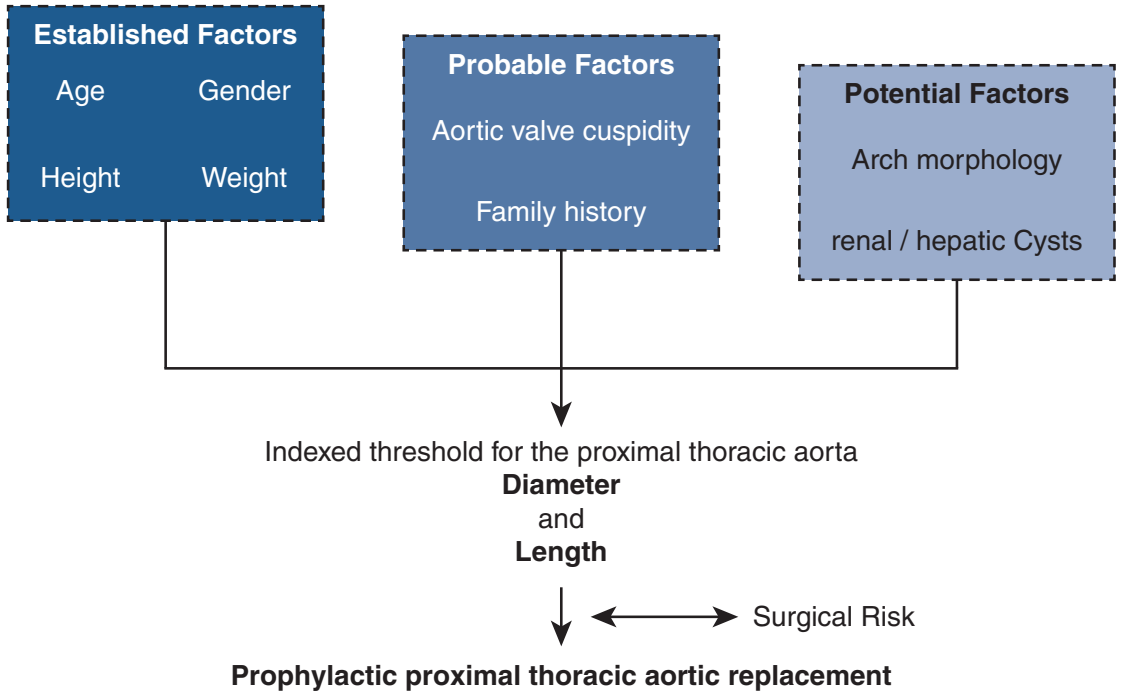

FIGURE 2. Modified decision algorithm of a future multifactorial risk model to indicate treatment for proximal thoracic aortic pathology. 
The rational way to legitimize prophylactic surgery is to identify certain constellations with defined risk for acute TAAD and weigh this against the surgical risk for elective proximal thoracic aortic surgery, which is currently quantified with $3.4 \%$ mortality and $3.2 \%$ risk of stroke but obviously varies significantly between centers. ${ }^{30} \mathrm{We}$ should make things as simple as possible, but not too simple. There are more factors that highly likely should refine prognostication: First, age and gender should be included in the assessment of aortic morphology, if only because large population-based studies have shown the dependence of aortic morphology on these factors (Evidence Level B). Aortic valve bicuspidity and family history are the next candidate predictive parameters that should be considered. Arch morphology and extra-aortic morphologic factors such as renal or hepatic cysts should be further evaluated as potential risk factors. Finally, parameters from functional imaging probably will emerge in the next 5 to 10 years.

How could joint efforts to generate data to close current gaps in knowledge look like? We should aim for a broader morphologic evaluation of patients with and without acute TAAD with respect to length because only this will enable a better understanding of the smooth transition between regular and pathologic, between normative and at risk. This will take a population-based transatlantic effort we are eagerly awaiting to initiate. The final result will highly likely be a multifactorial nomogram in which normative and threshold values for aortic morphology based on age, gender, height, and weight will be available. Figure 2 shows a modified decision algorithm to indicate treatment for proximal thoracic aortic pathology taking aortic length into account.

\section{CONCLUSIONS}

Our knowledge regarding the natural history of the disease has substantially increased, and all components addressed in this article have started to offer a broader 4dimensional picture that will help provide better patient care by doing the right things in indicating treatment in proximal thoracic aortic pathology, a field being the archetype of personalized medicine.

\section{Conflict of Interest Statement}

Outside this work, M.C. and B.R. are consultants to Terumo Aortic. M.C. is also a consultant to Medtronic and Endospan and received speaking honoraria from Cryolife-Jotec. All other authors reported no conflicts of interest.

The Journal policy requires editors and reviewers to disclose conflicts of interest and to decline handling or reviewing manuscripts for which they may have a conflict of interest. The editors and reviewers of this article have no conflicts of interest.

\section{References}

1. Coady MA, Rizzo JA, Hammond GL, Mandapati D, Darr U, Kopf GS, et al. What is the appropriate size criterion for resection of thoracic aortic aneurysms? J Thorac Cardiovasc Surg. 1997;113:476-91.

2. Erbel R, Aboyans V, Boileau C, Bossone E, Bartolomeo RD, Eggebrecht H, et al. 2014 ESC Guidelines on the diagnosis and treatment of aortic diseases: document covering acute and chronic aortic diseases of the thoracic and abdominal aorta of the adult. The Task Force for the Diagnosis and Treatment of Aortic Diseases of the European Society of Cardiology (ESC). Eur Heart J. 2014;35:2873-926.

3. Hiratzka LF, Bakris GL, Beckman JA, Bersin RM, Carr VF, Casey DE Jr, et al. 2010 ACCF/AHA/AATS/ACR/ASA/SCA/SCAI/SIR/STS/SVM guidelines for the diagnosis and management of patients with Thoracic Aortic Disease: a report of the American College of Cardiology Foundation/American Heart Association Task Force on Practice Guidelines, American Association for Thoracic Surgery, American College of Radiology, American Stroke Association, Society of Cardiovascular Anesthesiologists, Society for Cardiovascular Angiog raphy and Interventions, Society of Interventional Radiology, Society of Thoracic Surgeons, and Society for Vascular Medicine. Circulation. 2010;121:e266-369.

4. Kruger T, Oikonomou A, Schibilsky D, Lescan M, Bregel K, Vohringer L, et al. Aortic elongation and the risk for dissection: the Tubingen Aortic Pathoanatomy (TAIPAN) project. Eur J Cardiothorac Surg. 2017;51:119-26.

5. Rylski B, Blanke P, Beyersdorf F, Desai ND, Milewski RK, Siepe M, et al. How does the ascending aorta geometry change when it dissects? J Am Coll Cardiol. 2014;63:1311-9.

6. Pape LA, Tsai TT, Isselbacher EM, Oh JK, O'Gara PT, Evangelista A, et al. Aortic diameter $>$ or $=5.5 \mathrm{~cm}$ is not a good predictor of type A aortic dissection: observations from the International Registry of Acute Aortic Dissection (IRAD) Circulation. 2007;116:1120-7.

7. Mansour AM, Peterss S, Zafar MA, Rizzo JA, Fang H, Charilaou P, et al. Prevention of aortic dissection suggests a diameter shift to a lower aortic size threshold for intervention. Cardiology. 2018;139:139-46.

8. Paruchuri V, Salhab KF, Kuzmik G, Gubernikoff G, Fang H, Rizzo JA, et al. Aortic size distribution in the general population: explaining the size paradox in aortic dissection. Cardiology. 2015;131:265-72.

9. Turkbey EB, Jain A, Johnson C, Redheuil A, Arai AE, Gomes AS, et al. Determinants and normal values of ascending aortic diameter by age, gender, and race/ ethnicity in the Multi-Ethnic Study of Atherosclerosis (MESA). J Magn Reson Imaging. 2014;39:360-8.

10. Hardikar AA, Marwick TH. The natural history of guidelines: the case of aortopathy related to bicuspid aortic valves. Int J Cardiol. 2015;199:150-3.

11. Czerny M, Schmidli J, Adler S, van den Berg J, Bertoglio L, Carrel T, et al. Current options and recommendations for the treatment of thoracic aortic pathologies involving the aortic arch- an expert consensus document of the European Association for Cardio-Thoracic Surgery (EACTS) and the European Society of Vascular Surgery (ESVS). Eur J Cardiothorac Surg. 2019;55:133-62.

12. Wu J, Zafar MA, Li Y, Saeyeldin A, Huang Y, Zhao R, et al. Ascending aortic length and risk of aortic adverse events: the neglected dimension. J Am Coll Cardiol. 2019;74:1883-94.

13. Zafar MA, Li Y, Rizzo JA, Charilaou P, Saeyeldin A, Velasquez CA, et al. Heigh alone, rather than body surface area, suffices for risk estimation in ascending aortic aneurysm. J Thorac Cardiovasc Surg. 2018;155:1938-50.

14. Kruger T, Boburg RS, Hamdoun H, Oikonomou A, Bongers MN, Schlensak C Development of a multivariable prediction model for patient-adjusted aortic risk morphology. Eur J Cardiothorac Surg. 2020;58:692-9.

15. Kruger T, Forkavets O, Veseli K, Lausberg H, Vohringer L, Schneider W, et al Ascending aortic elongation and the risk of dissection. Eur $J$ Cardiothorac Surg. 2016;50:241-7.

16. Kruger T, Sandoval Boburg R, Lescan M, Oikonomou A, Schneider W, Vohringer L, et al. Aortic elongation in aortic aneurysm and dissection: the Tubingen Aortic Pathoanatomy (TAIPAN) project. Eur J Cardiothorac Surg. 2018;54:26-33.

17. Adriaans BP, Heuts S, Gerretsen S, Cheriex EC, Vos R, Natour E, et al. Aortic elongation part I: the normal aortic ageing process. Heart. 2018;104:1772-7.

18. Heuts S, Adriaans BP, Gerretsen S, Natour E, Vos R, Cheriex EC, et al. Aortic elongation part II: the risk of acute type A aortic dissection. Heart. 2018;104: $1778-882$

19. Girdauskas E, Disha K, Borger MA, Kuntze T. Risk of proximal aortic dissection in patients with bicuspid aortic valve: how to address this controversy? Interact Cardiovasc Thorac Surg. 2014;18:355-9.

20. Kim JB, Spotnitz M, Lindsay ME, MacGillivray TE, Isselbacher EM, Sundt TM 3rd. Risk of aortic dissection in the moderately dilated ascending aorta. J Am Coll Cardiol. 2016;68:1209-19. 
21. Borger MA, Fedak PWM, Stephens EH, Gleason TG, Girdauskas E, Ikonomidis JS, et al. The American Association for Thoracic Surgery consensus guidelines on bicuspid aortic valve-related aortopathy: full online-only version. $J$ Thorac Cardiovasc Surg. 2018;156:e41-74.

22. Dumfarth J, Chou AS, Ziganshin BA, Bhandari R, Peterss S, Tranquilli M, et al Atypical aortic arch branching variants: a novel marker for thoracic aortic disease. J Thorac Cardiovasc Surg. 2015;149:1586-92.

23. Ziganshin BA, Theodoropoulos P, Salloum MN, Zaza KJ, Tranquilli M, Mojibian HR, et al. Simple renal cysts as markers of thoracic aortic disease. $J$ Am Heart Assoc. 2016;5:e002248.

24. Ma WG, Chou AS, Mok SCM, Ziganshin BA, Charilaou P, Zafar MA, et al. Positive family history of aortic dissection dramatically increases dissection risk in family members. Int J Cardiol. 2017;240:132-7.

25. Morrison TM, Choi G, Zarins CK, Taylor CA. Circumferential and longitudinal cyclic strain of the human thoracic aorta: age-related changes. J Vasc Surg. 2009; 49:1029-36.

26. Iliopoulos DC, Kritharis EP, Giagini AT, Papadodima SA, Sokolis DP. Ascending thoracic aortic aneurysms are associated with compositional remodeling and vessel stiffening but not weakening in age-matched subjects. $J$ Thorac Cardiovasc Surg. 2009;137:101-9.

27. Plonek T, Zak M, Rylski B, Berezowski M, Czerny M, Beyersdorf F, et al. Wall stress correlates with intimal entry tear localization in Type A aortic dissection. Interact Cardiovasc Thorac Surg. 2018;27:797-801.

28. Nathan DP, Xu C, Gorman JH 3rd, Fairman RM, Bavaria JE, Gorman RC, et al. Pathogenesis of acute aortic dissection: a finite element stress analysis. Ann Thorac Surg. 2011;91:458-63.

29. Nchimi A, Cheramy-Bien JP, Gasser TC, Namur G, Gomez P, Seidel L, et al. Multifactorial relationship between $18 \mathrm{~F}$-fluoro-deoxy-glucose positron emission tomography signaling and biomechanical properties in unruptured aortic aneurysms. Circ Cardiovasc Imaging. 2014;7:82-91.

30. Williams JB, Peterson ED, Zhao Y, O’Brien SM, Andersen ND, Miller DC, et al. Contemporary results for proximal aortic replacement in North America. J Am Coll Cardiol. 2012;60:1156-62.

Key Words: aortic diameter, aortic length, ascending aortic aneurysm, indication, type A aortic dissection 